\title{
THE GENERALIZED STACKELBERG EQUILIBRIUM OF THE ALL-PAY AUCTION WITH COMPLETE INFORMATION
}

\author{
KAI A. KONRAD \\ WOLFGANG LEININGER
}

CESIFO WORKING PAPER NO. 1609

CATEGORY 9: INDUSTRIAL ORGANISATION

NOVEMBER 2005

An electronic version of the paper may be downloaded

- from the SSRN website:

www.SSRN.com

- from the CESifo website:

www.CESifo-group.de 


\title{
THE GENERALIZED STACKELBERG EQUILIBRIUM OF THE ALL-PAY AUCTION WITH COMPLETE INFORMATION
}

\begin{abstract}
We characterize the equilibrium of the all-pay auction with general convex cost of effort and sequential effort choices. We consider a set of $n$ players who are arbitrarily partitioned into a group of players who choose their efforts 'early' and a group of players who choose 'late'. Only the player with the lowest cost of effort has a positive payoff in any equilibrium. This payoff depends on his own timing vis-a-vis the timing of others. We also show that the choice of timing can be endogenized, in which case the strongest player typically chooses 'late', whereas all other players are indifferent with respect to their choice of timing. In the most prominent equilibrium the player with the lowest cost of effort wins the auction at zero aggregate cost.
\end{abstract}

JEL Code: D72, D74.

Keywords: sequential all-pay auction, complete information, generalized cost, generalized Stackelberg game.

Kai A. Konrad

Social Science Research Center Berlin

(WZB)

Reichpietschufer 50

10785 Berlin

Germany

kkonrad@wz-berlin.de

\author{
Wolfgang Leininger \\ University of Dortmund \\ Department of Economics \\ 44221 Dortmund \\ Germany \\ wolfgang.leininger@udo.edu
}

September 2005

Wolfgang Leininger likes to express his gratitude to Wissenschaftszentrum Berlin (WZB) for its generous hospitality and financial support. 


\section{Introduction}

The analytics of the all-pay auction with complete information with simultaneous choices of efforts by several contestants is well understood. Hillman and Riley (1989) were first to characterize an equilibrium, and Baye, Kovenock and de Vries (1996) provide a complete characterization of the set of equilibria for the case in which contestants have linear cost of expending effort. It is clear from the analysis in Kaplan, Luski and Wettstein (2003) that the solution concept of the case with linear cost carries over to cases in which contestants have non-linear cost of expending effort. Other analyses contributing to the solution of the all-pay auction with complete information are Hillman and Samet (1987) who, among other aspects, consider the problem of entry fees or minimum contest efforts, and Baye, Kovenock and de Vries (2005) who work out the complete analytic solution for all-pay auctions with two players and various cost of effort functions, in which a player's total cost of effort may generally depend on the own effort expended, on the effort that is expended by the rival player, and on the outcome of the contest. All these analyses consider simultaneous effort choices.

Simultaneity of effort choices cannot be taken for granted for situations in which all-pay auctions take place. Particularly when the conflict has some asymmetry properties, sequential effort choices may emerge naturally from the institutional environment, or even endogenously. Leininger (1991) models a patent race between incumbent and entrant, who value the patent differently, as a sequential all-pay auction with possibly repeated bidding under complete information. Konrad (2002) considers an all-pay auction with two asymmetric players. He mostly concentrates on symmetric moves, but also discusses the implications of sequential effort choices for the equilibrium outcome in a specific analytic context, allowing for two types of incumbency advantages. Jost and Kräkel (2005) also look at this specific problem and compare the outcomes for sequential and simultaneous choices for the case with two players. Moreover, they consider a contest success function with noise. The more general case in which there is a set with more than two players who are partitioned in two disjoint subsets of which the members of one subset choose effort prior to the members of the other subset has not been considered. This paper solves for this generalized Stackelberg equilibrium, and with a generalized cost function.

We also discuss the issue of endogenous sequentiality that emerges in a contest environment. In the context of the Tullock (1980) contest, Baik and 
Shogren (1992), Leininger (1993), Baik (1994, 2005) and Wärneryd (2000) provide analyses of this problem. Suppose there are two points in time at which contest effort can be expended. One point is called $e$ (arly), the other is called $l$ (ate). In a stage prior to $e$, contestants can choose whether to make their contest effort choices at $e$ or at $l$. It turns out that, if the effort choices at $e$ are irreversibly made, the "weaker" player has an incentive to choose $e$ and the "stronger" player has an incentive to choose $l$. In the end, both contestants are better off. We analyse in this paper how the result on endogenous timing generalizes to a larger set of asymmetric players for the all-pay auction with complete information.

\section{Equilibrium}

A prize of given size $V=1$ is allocated among a set $N$ of players $i=1, \ldots n$ in an all-pay auction with complete information. Let $\mathbf{x}=\left(x_{1}, x_{2}, \ldots x_{n}\right)$ denote the vector of players' efforts. Each player chooses his effort irreversibly at a particular point of time. The players in a subset $E \subset N$ choose their efforts simultaneously at a point $e$ (arly) and players from set $L=N-E$ choose their efforts at point $l$ (ate), where $l$ occurs after $e$, such that players who are in set $L$ can observe the effort choices made by the players who are in set $E$.

Players are risk neutral. A player's payoff is

$$
\pi_{i}(\mathbf{x})=p_{i}(\mathbf{x}) \cdot 1-C_{i}\left(x_{i}\right) .
$$

Here the $\operatorname{cost} C_{i}\left(x_{i}\right)$ of expending a given effort $x_{i}$ is a function of this effort, and we will assume throughout that $C_{i}(0)=0, C_{i}^{\prime}\left(x_{i}\right)>0$, and $C_{i}^{\prime \prime}\left(x_{i}\right) \geq 0$. The standard cases with linear cost, $C_{i}\left(x_{i}\right)=c_{i} x_{i}$, and with quadratic cost, $C_{i}\left(x_{i}\right)=c_{i}\left(x_{i}\right)^{2}$ are special cases. We assume that players are asymmetric and can be sorted according to their effort cost. Without loss of generality we consider them numbered such that, for two players $i$ and $j$ with $i<j$, it holds that $C_{i}^{\prime}(x)<C_{j}^{\prime}(x)$ for all $x \in(0, K]$. This global asymmetry rules out a number of equilibria that may occur if some players are identical. Note that, according to this sorting assumption, player 1 has the lowest cost for expending a given effort, player 2 has the second lowest cost, etc. The sorting of players in $N$ according to their cost of effort also induces a similar sorting of players in $E$ and in $L$, and we re-number the players in $E$ and $L$ according to their cost functions as $e_{(1)}, e_{(2)}, \ldots, e_{(\# E)}$ with $C_{e_{(i)}}(x)<C_{e_{(j)}}(x)$ and $l_{(1)}, l_{(2)}, \ldots, l_{(\# L)}$ with $C_{l_{(i)}}(x)<C_{l_{(j)}}(x)$ for all $i<j$ for all $x>0$. 
The probability that player $i$ wins the prize is denoted as $p_{i}$, and is a function of $\mathbf{x}$, as follows. Denote $\bar{x} \equiv \max _{k \in N}\left\{x_{k}\right\}$. If $x_{i}=\bar{x}>x_{j}$ for all $j \in N-\{i\}$, then $p_{i}=1$ and $p_{j}=0$ for all $j \neq i$. If there are several players who have chosen the same, highest effort, $\bar{x}$, we assume the following tie-breaking rule. Let $M$ be the set of players who choose $\bar{x}$. If $M \subset E$, or $M \subset L$, then each $i \in M$ wins the prize with the same probability equal to $1 / \# M$, where $\# M$ is the cardinality of $M$. If $M \cap E \neq \varnothing$ and $M \cap L \neq \varnothing$ then the allocation of the prize among the players in $M$ depends on their cost of effort. If $C_{i}(\bar{x}) \geq 1$ for all $i \in M \cap L$, then $p_{i}=1 / \#(M \cap E)$ for $i \in M \cap E$ and zero for all other players. Denote $(M \cap L)^{+}(\bar{x})$ the subset of $(M \cap L)$ with players for which $C_{i}(\bar{x})<1$ holds. If $(M \cap L)^{+}(\bar{x}) \neq \varnothing$, then $p_{i}=1 / \#(M \cap L)^{+}(\bar{x})$ for $i \in(M \cap L)^{+}(\bar{x})$ and $p_{i}=0$ for all other players.

Strategies are defined as follows. For a player $i \in E$, a pure strategy is an effort choice $x_{i}$ and the strategy set of player $i$ is the set of feasible efforts $[0, K]$, with $K$ being a finite number that is sufficiently large to be never binding. ${ }^{1}$ We also define a mixed strategy $F_{i}$ for player $i \in E$ as an element of the set of probability distributions over the effort levels from the set $[0, K]$. A player $i \in L$ observes the effort choices of all players $j \in E$. We denote the vector of these effort choices by all players from $E$ as $\mathbf{x}_{E}$. As it turns out only $\bar{x}_{E}$, the maximal component of $\mathbf{x}_{E}$, is payoff relevant for the game in period $l$. Hence we can denote a pure strategy of player $i \in L$ as a function $x_{i}\left(\bar{x}_{E}\right):[0, K] \rightarrow[0, K]$, and a mixed strategy of this player as a function $F_{i}\left(\bar{x}_{E}\right):[0, K] \rightarrow \Sigma_{[0, K]}$, where $\Sigma_{[0, K]}$ denotes the set of probability distributions over the effort levels from the set $[0, K]$.

Proposition 1 For any given sets $L$ and $E$ there exists a unique subgame perfect equilibrium of the (sequential) all-pay auction. Equilibrium pay-offs are given by:

$$
\begin{gathered}
\pi_{j}=0 \text { for all } j=2, \ldots n, \text { and } \\
\pi_{1}=\left\{\begin{array}{cc}
1 & \text { if } L=\{1\} \\
1-C_{1}\left(\bar{x}_{l_{(2)}}\right) & \text { if } 1 \in L \text { and } \# L>1 \\
1-C_{1}\left(\bar{x}_{2}\right) & \text { if } 1 \in E
\end{array} \quad \text { with } \bar{x}_{2} \text { the solution of } C_{2}\left(\bar{x}_{2}\right)=1\right.
\end{gathered}
$$

Proof. Consider first stage $l$. Denote $\bar{x}_{E}=\max _{e_{(i)} \in E}\left\{x_{e_{(i)}}\right\}$. Recall that $e_{(i)}$ are the players of set $E$ ordered along ascending cost functions. Let

\footnotetext{
${ }^{1}$ For instance, it will be sufficient to define $K$ as the solution of $C_{1}(K)=1$.
} 
$L^{+}\left(\bar{x}_{E}\right)$ be the set of players $k \in L$ for which $C_{k}\left(\bar{x}_{E}\right)<1$, and $L^{-}\left(\bar{x}_{E}\right)$ the set of the players $k \in L$ for which $C_{k}\left(\bar{x}_{E}\right) \geq 1$.

Consider the following candidate equilibrium of the subgame at stage $l$. (i) All players $k \in L^{-}\left(\bar{x}_{E}\right)$ choose $x_{k}\left(\mathbf{x}_{E}\right)=0$. (ii) For players $k \in L^{+}\left(\bar{x}_{E}\right)$, if $\# L^{+}\left(x_{E}\right)=1$ then $x_{k}\left(\mathbf{x}_{E}\right)=\bar{x}_{E}$. If $\# L^{+}\left(x_{E}\right)>1$, then $x_{k}\left(\mathbf{x}_{E}\right)=0$ for all $k \in L$ with $k \notin\left\{l_{(1)}, l_{(2)}\right\}$,

$$
F_{l_{(1)}}\left(\mathbf{x}_{E}\right)=\left\{\begin{array}{ccc}
0 & \text { for } & x \in\left[0, \bar{x}_{E}\right) \\
C_{l_{(2)}}(x) & \text { for } & x \in\left[\bar{x}_{E}, \bar{x}_{l_{(2)}}\right] \\
1 & \text { for } & x>\bar{x}_{l_{(2)}}
\end{array}\right.
$$

and

$$
F_{l_{(2)}}\left(\mathbf{x}_{E}\right)=\left\{\begin{array}{ccc}
1-C_{l_{(1)}}\left(\bar{x}_{l_{(2)}}\right)+C_{l_{(1)}}\left(\bar{x}_{E}\right) & \text { for } & x \in\left[0, \bar{x}_{E}\right] \\
1-C_{l_{(1)}}\left(\bar{x}_{l_{(2)}}\right)+C_{l_{(1)}}(x) & \text { for } & x \in\left(\bar{x}_{E}, \bar{x}_{l_{(2)}}\right] \\
1 & \text { for } & x>\bar{x}_{l_{(2)}} .
\end{array}\right.
$$

To confirm that this constitutes an equilibrium we show that these strategies are mutually optimal replies. (i) For given $\bar{x}_{E}, x_{k}=0$ uniquely maximizes the payoff of players $k \in L^{-}\left(\bar{x}_{E}\right)$, independent of the choices of other players in $L$. (ii) Consider $k \in L^{+}\left(x_{E}\right)$ with $k \notin\left\{l_{(1)}, l_{(2)}\right\}$. The payoff in the candidate equilibrium is $\pi_{k}(0)=0$ and, given (??), $\pi_{k}\left(x_{k}\right)<0$ for any $x_{k}>0$. Thus $x_{k}=0$ is the unique best reply. Consider next $l_{(1)}$. The payoff of this player given the candidate equilibrium strategies of other players is $\pi_{l_{(1)}}(0)=0, \pi_{l_{(1)}}(x)=-C_{l_{(1)}}(x)$ for $x \in\left(0, \bar{x}_{E}\right)$ and

$$
\pi_{l_{(1)}}=F_{l_{(2)}}(x) \cdot 1-C_{l_{(1)}}(x)
$$

for $x_{l_{(1)}} \geq \bar{x}_{E}$. This payoff is equal to $1-C_{l_{(1)}}\left(\bar{x}_{l_{(2)}}\right)>0$ for all $x_{l_{(1)}} \in\left[\bar{x}_{E}\right.$, $\bar{x}_{l_{(2)}}$, because of (5), and smaller than this for all $x$ outside this interval. Consider finally the payoff of $l_{(2)}$. This payoff is $\pi_{l_{(2)}}=0$ for $x_{l_{(2)}}=0$, $\pi_{l_{(2)}}(x)=-C_{l_{(2)}}(x)$ for $x \in\left(0, \bar{x}_{E}\right)$, and

$$
\pi_{l_{(2)}}=F_{l_{(1)}}(x) \cdot 1-C_{l_{(2)}}(x)
$$

for $x_{l_{(2)}}>\bar{x}_{E}$. This payoff (??) is equal to zero for all $x_{l_{(2)}} \in\left(\bar{x}_{E}, \bar{x}_{l_{(2)}}\right]$, because of (4), and negative for all $x$ outside this interval. Accordingly, any $x \in\{0\} \cup\left(\bar{x}_{E}, \bar{x}_{l_{(2)}}\right]$ is an optimal reply for $l_{(2)}$.

Note that the equilibrium in the subgame among players from set $L$ is the equilibrium of a simultaneous all-pay auction with a minimum bid of 
$\bar{x}_{E}$. The uniqueness of this equilibrium can be shown following the line of arguments in Baye, Kovenock and de Vries (1996).

Consider now stage $e$. Define $\max _{l_{(i)} \in L}\left\{\bar{x}_{l_{(i)}}\right\} \equiv \bar{x}_{L}$. An implication of the subgame equilibrium is that a player from the set $E$ who made the highest bid $\bar{x}_{E}$ among all players from this group wins the prize if and only if $\bar{x}_{E}>\bar{x}_{L}$. Intuitively, in the characterization of the equilibrium strategies of players from the set $L$, this $\bar{x}_{L}$ plays a similar role for players from the set $E$ when they choose their efforts, as $\bar{x}_{E}$ does in the subgame when players from the set $L$ make their choices. Note, that $\bar{x}_{L}$, unlike $\bar{x}_{E}$, is not determined by the actual effort choices of players, but is uniquely determined by the cost structure of the players in $L$. Hence, somewhat surprisingly, the game among players at stage $e$, too, has the structure of a simultaneous all-pay auction with a minimum bid, which now is given by $\bar{x}_{L} \cdot \bar{x}_{L}$ results from foreseeing the optimal behaviour of players moving at $l$. Uniqueness of this equilibrium then again follows from Baye, Kovenock and de Vries (1996) for any set $E$ and any $\bar{x}_{L}$.

Let $E^{+}\left(\bar{x}_{L}\right)$ be the set of players $k$ in $E$ for which $C_{k}\left(\bar{x}_{L}\right)<1$, and $E^{-}\left(\bar{x}_{L}\right)$ the set of players $k$ in $E$ for which $C_{k}\left(\bar{x}_{L}\right)>1$. Note that $C_{k}\left(\bar{x}_{L}\right)=1$ for $k \in E$ is ruled out by $C_{k}\left(\bar{x}_{L}\right)=1$ for some $k \in L$ and the fact that all players in $N$ differ in their cost functions. We consider the following candidate equilibrium for effort choices among players from the set $E$. (i) All players $k \in E^{-}\left(\bar{x}_{L}\right)$ choose $x_{k}=0$. (ii) If $\# E^{+}\left(\bar{x}_{L}\right)=1$, then this player $k \in E^{+}\left(\bar{x}_{L}\right)$ chooses $x_{k}=\bar{x}_{L}$. (iii) If $\# E^{+}\left(\bar{x}_{L}\right)>1$, then all players $e_{(k)} \in E^{+}\left(\bar{x}_{L}\right)$ with $k>2$ choose $x_{e_{(k)}}=0$, player $k=e_{(1)}$ chooses a mixed strategy that is described by the cumulative distribution function

$$
F_{e_{(1)}}=\left\{\begin{array}{ccc}
0 & \text { for } & x \in\left[0, \bar{x}_{L}\right) \\
C_{e_{(2)}}(x) & \text { for } & x \in\left[\bar{x}_{L}, \bar{x}_{e_{(2)}}\right] \\
1 & \text { for } & x>\bar{x}_{e_{(2)}}
\end{array}\right.
$$

and player $k=e_{(2)}$ chooses a mixed strategy that is described by the cumulative distribution function

$$
F_{e_{(2)}}=\left\{\begin{array}{clc}
1-C_{e_{(1)}}\left(\bar{x}_{e_{(2)}}\right)+C_{e_{(1)}}\left(\bar{x}_{L}\right) & \text { for } & x \in\left[0, \bar{x}_{L}\right] \\
1-C_{e_{(1)}}\left(\bar{x}_{e_{(2)}}\right)+C_{e_{(1)}}(x) & \text { for } & x \in\left(\bar{x}_{L}, \bar{x}_{e_{(2)}}\right] \\
1 & \text { for } & x>\bar{x}_{e_{(2)}}
\end{array}\right.
$$

We show that this constitutes equilibrium strategies by showing that the candidate equilibrium strategies are mutually optimal replies given the equilibrium of the subgame among players in $L$. A key aspect of the subgame 
equilibrium is that players from $L$ will overbid any effort $x$ made in stage $e$ that is smaller than $\bar{x}_{L}$. (i) Consider $k \in E^{-}\left(\bar{x}_{L}\right)$. A choice of $x_{k}=0$ yields $\pi_{k}(0)=0$. Effort levels $0<x_{e_{(i)}}<\bar{x}_{L}$ yield a payoff $\pi_{k}=-C_{k}\left(x_{k}\right)<0$ and effort levels $x_{k} \geq \bar{x}_{L}$ have cost $C_{k}\left(x_{k}\right)$ that exceed the value of the prize for $k \in E^{-}\left(\bar{x}_{L}\right)$, leading to a negative payoff, even if $k$ wins the prize with this effort choice. Note that this also holds for the possible effort choice case $x_{k}=\bar{x}_{L}$ : by the definition of $\bar{x}_{L}$ as the solution to $C_{l_{(1)}}\left(\bar{x}_{L}\right)=1$, the definition of $E^{-}\left(\bar{x}_{L}\right)$ and the strict monotonicity of cost functions of all players in $N$, strict inequality $C_{e_{(i)}}\left(\bar{x}_{L}\right)>1$ must hold for all $e_{(i)} \in E^{-}\left(\bar{x}_{L}\right)$. Accordingly, $x_{k}=0$ is the unique optimal reply for $k \in E^{-}\left(\bar{x}_{L}\right)$. (ii) Consider $k \in E^{+}\left(\bar{x}_{L}\right)$. If $\# E^{+}\left(\bar{x}_{L}\right)=1$, the only player in this set has to be player 1 , i.e., the player with the lowest cost among all players in $N$. Moreover, $\# E^{+}\left(\bar{x}_{L}\right)=1$ implies that the player with the second lowest cost is in the set $L$, i.e., $2=l_{(1)} \in L$. Therefore, $\bar{x}_{L}=\bar{x}_{2}$. Player 1's payoff is $\pi_{1}\left(\bar{x}_{2}\right)=1-C_{1}\left(\bar{x}_{2}\right)>0$ if $x_{1}=\bar{x}_{2}$. Player 1's payoff from $x_{1}<\bar{x}_{2}$ is equal to $-C_{1}\left(x_{1}\right) \leq 0$, and $\pi_{1}\left(x_{1}\right)=1-C_{1}\left(x_{1}\right)<1-C_{1}\left(\bar{x}_{2}\right)$ for $x_{1}>\bar{x}_{2}$. Accordingly, $x_{1}=\bar{x}_{2}$ is the optimal reply. (iii) Consider $\# E^{+}\left(\bar{x}_{L}\right)>1$. The payoff of player $k \in E^{+}\left(\bar{x}_{L}\right)$ with $k \notin\left\{e_{(1)}, e_{(2)}\right\}$ is $\pi_{k}(0)=0$ for $x_{k}=0, \pi_{k}\left(x_{k}\right)=-C_{k}\left(x_{k}\right)<0$ for all $0<x_{k}<\bar{x}_{L}$, and, given (??), $\pi_{k}\left(x_{k}\right)<0$ also for all $x_{k} \geq \bar{x}_{L}$. Hence $x_{l(k)}=0$ is the optimal play. Note that $\# E^{+}\left(\bar{x}_{L}\right)>1$ implies that $e_{(1)}=1$ and $e_{(2)}=2$. Player 2's payoff is equal to $p_{2}(x) \cdot 1-C_{2}\left(x_{2}\right)$. Using the candidate equilibrium strategies of all other players in $E$ and the properties of the unique equilibrium of the subgame, $\pi_{2}(0)=0$ for $x_{2}=0, \pi_{2}\left(x_{2}\right)=-C_{2}\left(x_{2}\right)<0$ for $0<x_{2}<\bar{x}_{L}$, $\pi_{2}\left(x_{2}\right)=0$ for $x_{2} \in\left[\bar{x}_{L}, \bar{x}_{2}\right]$, and $\pi_{2}\left(x_{2}\right)=1-C_{2}\left(x_{2}\right)<0$ for $x_{2}>\bar{x}_{2}$. Accordingly, any bid from the support $\{0\} \cup\left(\bar{x}_{L}, \bar{x}_{2}\right]$ is an optimal reply for player 2. Finally, player 1's payoff is $\pi_{1}(x)=p_{1}(x) \cdot 1-C_{1}\left(x_{1}\right)$. Given the candidate equilibrium strategies of other players $k \in E$ and the effort choices in the subgame perfect equilibrium this payoff is equal to $1-C_{1}\left(\bar{x}_{2}\right)>0$ for all $x_{1} \in\left[\bar{x}_{L}, \bar{x}_{2}\right]$ and smaller for all other $x_{1}$. Accordingly, any bid from the interval $\left[\bar{x}_{L}, \bar{x}_{2}\right]$ is an optimal reply for player 1 . Hence, the mixed strategies $F_{l(1)}$ and $F_{l(2)}$ are best replies to each other.

In the candidate equilibrium, $\pi_{k}=0$ for all $k \neq 1$. Consider $\pi_{1}$. If $1 \in L$, then $x_{k}=0$ for all $k \in E$. Hence, $\bar{x}_{E}=0$. If $L=\{1\}$, then 1 wins with no effort and has payoff $\pi_{1}=1$. If $\# L>1$, then $\pi_{1}=1-C_{1}\left(\bar{x}_{l_{(2)}}\right)$. If $1 \in E$, it has been shown that $x_{1}=\bar{x}_{2}$ is within player 1's equilibrium support and yields $\pi_{1}=1-C_{1}\left(\bar{x}_{2}\right)$. This concludes the proof.

Proposition 1 shows, that - given our tie-breaking rule - for any partition 
of players into the sets $E$ and $L$, there is a unique subgame perfect equilibrium. Since the number of different partitions of $n$ players into two sets is $2^{n}$, we have characterized $2^{n}$ possible equilibrium configurations. Note however that these result in only $n$ different equilibrium payoff vectors $\left(\pi_{1}, 0, \ldots, 0\right)$, where $\pi_{1}$ can assume the values 1 and $1-C_{1}\left(\bar{x}_{i}\right), i=2, . ., n$. Adding another player $(n+1)$ would double the number of feasible partitions (as this player could "join" any previous partition in either E or L), but add only one further equilibrium payoff vector $\boldsymbol{\pi}=\left(1-C_{1}\left(\bar{x}_{n+1}\right), 0, \ldots, 0\right)$ with a new positive payoff for player 1 . If the new player would not be the one with the highest cost of effort (and hence change our labelling of players), it would still be true that the number of different equilibrium payoffs for player 1 only increases by one to $(n+1)$. Moreover, $n$ of those are identical to the previous ones unless the new player happens to be the -new- strongest one with the lowest cost of effort. In this latter case all $n$ feasible equilibrium payoffs for player 1 , which are smaller than 1 , can be different from the previous feasible equilibrium values with only $n$ players. With just 2 players the equilibrium payoffs for three player partitions $\left(E_{1}, L_{1}\right)=(\{1\},\{2\}),\left(E_{2}, L_{2}\right)=(\{1,2\},\{\emptyset\})$ and $\left(E_{3}, L_{3}\right)=(\{\emptyset\},\{1,2\})$ are identically equal to $\left(1-C_{1}\left(\bar{x}_{2}\right), 0\right)$, whereas $\left(E_{4}, L_{4}\right)=(\{2\},\{1\})$ yields the payoffs $(1,0)$.

Proposition 1 also shows that the equilibrium of the generalized Stackelberg equilibrium has similar properties as the solution with two players. Only the player with the strongest cost advantage has a positive payoff, and this payoff is larger if this player chooses his effort last. An interesting aspect is that the all-pay auction that takes place at stage $l$ and the competition it involves for those players, does not benefit the players who choose at stage $e$ compared to the situation in which there is only one player who chooses late. The reason is that $\bar{x}_{L}$, the minimal bid for a player in $\mathrm{E}$ in order to win, does not depend on actual behavior of players in the competition at $\mathrm{L}$, but their potential limit behavior in rational play. This largest possible rational counter bid, however, is determined by exogenous data, namely the cost parameters of the players moving at L. Also similar to the two-player case, the player with the lowest cost is best off if he moves later than all other players. For all other players, timing does not affect their payoff. They all cannot expect to gain something from participating in the contest and from making positive bids. These results do not depend in an essential way on our choice of tie-breaking rule. This rule was chosen in order to arrive at strict subgame perfect equilibria. Choice of other tie-breaking rules; i.e. the probably more "'obvious"' one, which stipulates the winning probability of 
a player from $M$ as always equal to $\frac{1}{\# M}$ regardless of his membership in $E$ or $L$, would only produce $\varepsilon$-equilibria. Moreover, these $\varepsilon$-equilibria would all lie in $\varepsilon$-neighborhoods of our strict equilibria.

\section{$3 \quad$ Endogenous timing}

Let $N$ continue to be the set of players, but consider a game that is "enlarged" by a decision stage 1 that occurs prior to stage $e$. In stage 1 each player $k \in N$ chooses whether to choose effort at stage $e$ or at stage $l$, and may randomize, in which case $q_{k} \in[0,1]$ denotes the probability by which $k$ chooses $e$ and $\left(1-q_{k}\right)$ the probability by which $k$ chooses $l$. Once all players have chosen their $q_{k}$, the actual timing $t_{k} \in\{e, l\}$ of each player $k$ 's effort choice is determined and observed by all players. Let $\mathbf{t}=\left(t_{1}, \ldots t_{n}\right)$ denote the vector describing this set of actual timing, which emerges as a draw from $\mathbf{Q}$ that denotes the joint probability distribution over (independent) timing choices.

Note that a given $\mathbf{t}$ sorts the players into sets $E(\mathbf{t})$ and $L(\mathbf{t})$ which constitute a partition of $N$, and that there is a one-to-one mapping between feasible $\mathbf{t}$ and feasible partitions of $N$ into two sets $E$ and $L$.

At stage $e$, the history of the game is described by $(\mathbf{Q}$ and $) \mathbf{t}$. If $t_{k}=e$, then player $k$ must choose his effort $x_{k} \in[0, K]$, and this choice can be a function of this history. He may choose to randomize and choose effort as a draw from a cumulative distribution function $F_{k}$ as a function which generally can be a function of the history at stage $e$. Players with $t_{k} \neq e$ cannot take any action at this point. At the end of stage $e$, all players $k$ with $t_{k}=e$ have chosen their actions, and their actual efforts $x_{k}$ are observed by all players. The vector $\mathbf{x}_{E}$ describes these actual efforts.

The history of the game at stage $l$ is characterized by $\left(\mathbf{Q}, \mathbf{F}_{E},\right) \mathbf{t}$ and $\mathbf{x}_{E}$, (where $\mathbf{F}_{E}$ denotes the joint distribution function from which actual effort choices $\mathbf{x}_{E}$ have been drawn independently.) Players $k$ with $t_{k}=l$ must choose an effort level $x_{k} \in[0, K]$ and may choose effort as a function of the history. They may also randomize and choose according to a cumulative distribution function $F_{k}$. Players $k$ with $t_{k} \neq l$ cannot assume any action at this point.

At the end of stage $l$ the prize is awarded to the player who expended the highest effort, and the same tie-breaking rule as in section 2 is used if several players expended the same highest amount of effort.

Note that because of uniqueness of equilibrium at stage $l$ given $x_{E}$ (and 
$t$ ), it is irrelevant, which distributions $\mathbf{Q}$ resp. $\mathbf{F}_{E}$ have generated these realizations. I.e. a player cannot condition his behavior at $l$ on $\mathbf{Q}$ resp. $\mathbf{F}_{E}$ given the realizations $x_{E}$ and $t$, which are observed by all players. The same argument then applies for players at stage $e$ : given $t$ and given the knowledge, that players at $l$ cannot condition behavior on $\mathbf{Q}$ and their choices of $\mathbf{F}_{E}$, a player at $e$ cannot condition his strategy choice on $\mathbf{Q}$ as $t$ already determines the unique subgame perfect equilibrium in the continuation game (see the proof of Proposition 1).

The following Proposition characterizes subgame-perfect equilibrium in the game with endogenous timing of effort decisions.

\section{Proposition 2}

i) $q_{1}=0$ is an almost strictly dominant strategy for player 1; i.e. it is the unique best reply to any choice of $\left(q_{2}, \ldots, q_{n}\right)$ by players 2 to $n$, for which $q_{2}>0$. For any $\left(q_{2}, \ldots, q_{n}\right)$ with $q_{2}=0$ any choice of $q_{1} \in[0,1]$ is a best reply for player 1 .

ii) Let $q_{1}=0$; then any choice of timing strategies from $[0,1]$ by players $2, \ldots, n$ is (part of) a subgame perfect equilibrium in the game with endogenous timing of effort decisions.

Proof. Note first that, by the one-to-one mapping between $\mathbf{t}$ and $E(\mathbf{t})$ and $L(\mathbf{t}), \mathbf{Q}$ induces a probability distribution over partitions $(E, L)$ of $N$. Note further that the equilibrium that is characterized in the proof of Proposition 1 for any given partition and with payoffs as in Proposition 1 for this partition, is the subgame perfect equilibrium of the continuation game of the "enlarged" game for which this partition emerges at the end of stage 1 . And only $\mathbf{t}$ (or, equivalently, the partition that is described by $\mathbf{t}$ ) constitutes the payoff-relevant history.

Hence players anticipate that the equilibrium that is characterized in Proposition 1 is played in the continuation games for any partition of $N$ into $E(\mathbf{t})$ and $L(\mathbf{t})$. We now show that for a player $k, k>1$, any $q_{k} \in[0,1]$ is an optimal choice regardless of the chosen $q_{l}$ by players $l \in\{1, \ldots, k-1, k+1, \ldots, n\}$. We then show, that $q_{k}=0$ in turn is an optimal reply for player 1 to any of these choices by players 2 to $n$, and uniquely so, if $q_{2}>0$.

Consider first $k>1$. Given any joint distribution over $\left(t_{1}, \ldots, t_{k-1}\right.$, $\left.t_{k+1}, \ldots, t_{n}\right)$, any $q_{k}$ leads to a probability distribution over partitions $E$ and $L$ from which one actual partition results. The payoff of player $k$ in the 
subgame perfect equilibrium for each of these partitions is $\pi_{k}=0$ by Proposition 1. Accordingly, any $q_{k}$ is an optimal reply to any joint distribution over $\left(t_{1}, \ldots, t_{k-1}, t_{k+1}, \ldots, t_{n}\right)$.

Turn now to $k=1$. Define $\mathbf{t}_{-1} \equiv\left(t_{2}, \ldots, t_{n}\right)$. For a given $\mathbf{t}_{-1}$, let $j_{\min }\left(\mathbf{t}_{-1}\right)=\min \left[j \in\{2, \ldots, n\} \mid t_{j}=l\right]$. Then the payoff of player 1 from choosing $q_{1}$ given $\mathbf{t}_{-1}$ is $\left(1-q_{1}\right)\left(1-C_{1}\left(\bar{x}_{j_{\min }\left(\mathbf{t}_{-1}\right)}\right)+q_{1}\left(1-C_{1}\left(\bar{x}_{2}\right)\right)\right.$ and this payoff is non-increasing in $q_{1}$ and strictly decreasing if $j_{\min }\left(\mathbf{t}_{-1}\right) \neq 2$. Player 1 is always strictly better off by choosing $l$ instead of $e$, if player 2's choice $q_{2}$ results in the realization of $t_{2}=e$. Player 1 is indifferent between $e$ and $l$ if and only if $t_{2}=l$. This, however, is ex ante; i.e. before the $q$ 's are (simultaneously) chosen, only assured, if $q_{2}=0$. As soon as $q_{2}$ leads with positive probability to the realization $t_{2}=l$, player 1 is ex ante better off by choosing $l$ with certainty; i.e. $q_{1}=0$.

The intuition for why other players are essentially indifferent about when to choose their effort is straightforward. They have a payoff of zero in the continuation game that starts with stage $e$, regardless of the partition of players between $E$ and $L$. This makes them indifferent regarding their own choice of timing. This argument does not apply in general for player 1 . If this player chooses his effort late, he essentially competes only with the players who also choose their effort late, as all players in $E$ who choose their effort early are induced to choose zero effort in the equilibrium that is characterized in Proposition 1. However, if player 1 chooses his effort early, he essentially competes with all other players, either simultaneously, or via the fact that they can react to his bid and consider whether to make a higher bid. The advantage of choosing late therefore is that all competitors who choose early drop out of the competition, and this advantage is bigger if the group of players who choose early includes the particularly strong players. In the extreme case in which all players $k \neq 1$ belong to $E$ and choose early, if player 1 chooses late, there is no competitor left and player 1 receives the prize without any effort, whereas, if he chooses early, he competes with the whole group of other players. This may explain why player 1 has a preference for moving late. The only case in which this preference is not strict is when player 2 also chooses late. In this case the show-down between these two strongest players is inevitable, and player 1 is indifferent whether to choose early and preemt player 2, or whether he enters into a simultaneous all-pay auction with this second-strongest player. But note that any offer of a small "premium" payment $\epsilon>0$ for moving early -either by the rules of the game or by player 1- would select the efficient equilibrium as the unique equilibrium 
(for all tie-breaking rules).

\section{Conclusions}

The equilibrium in an all-pay auction with complete information has some interesting properties if one allows for some generalizations that naturally extend the results on the two-player all-pay auction with sequential bids. We consider partitions of a larger group of players into two subsets. Players in one subset choose their effort individually and simultaneously, prior to the individual and simultaneous choices of members of the other group, and we consider the endogenous formation of such groups and their timing of bids. Main results are: the sequential structure of bids favors the strongest player, particularly if some of his strongest competitors have to make their bids prior to him. For an appropriate partition of players the prize is efficiently allocated to the strongest bidder, with aggregate bid cost in this equilibrium of zero. Moreover, this partition of players into groups can emerge as an equilibrium outcome if all players choose their timing of bids simultaneously in a stage prior to the actual bidding stages. Hence our simple redesign of the simultaneous all-pay auction as a Stackelberg game yields an extremely efficient allocation mechanism for competitions, which involve (partially) wasteful bids or effort choices. In the prominent equilibrium, in which player 1 is the only one to move late, the prize is allocated efficiently with no "rent dissipation" at all!

\section{References}

[1] Baik, Kyung Hwan, 2005, Endogenous timing and effort levels in twoplayer asymmetric contests, mimeo., Sungkyunkwan University.

[2] Baik, Kyung Hwan, and Jason F. Shogren, 1992, Strategic behavior in contests: comment, American Economic Review, 82(1), 359-362.

[3] Baye, Michael R., Dan Kovenock and Casper G. de Vries, 1996, The allpay auction with complete information, Economic Theory, 8, 362-380.

[4] Baye, Michael R., Dan Kovenock and Casper G. de Vries, 2005, Comparative analysis of litigation systems: an auction-theoretic approach, Economic Journal, 115, 583-601. 
[5] Hillman, Arye, and John G. Riley, 1989, Politically contestable rents and transfers, Economics and Politics, 1, 17-40.

[6] Hillman, Arye L., Dov Samet, 1987, Dissipation of contestable rents by small numbers of contenders, Public Choice, 54(1), 63-82.

[7] Jost, Peter, and Matthias Kräkel, 2005, Preemptive behavior in simultaneous- and sequential-move tournaments with heterogenous agents, Economics of Governance (forthcoming).

[8] Kaplan, T.R., I. Luski and D. Wettstein, 2003, Innovative activity and sunk cost, International Journal of Industrial Organization, 21(8), 11111133.

[9] Konrad, Kai A., 2002, Investment in the absence of property rights; the role of incumbency advantages, European Economic Review, 46(8), 1521-1537.

[10] Leininger, Wolfgang, 1991, Patent Competition, Rent Dissipation and the Persistence of Monopoly, Journal of Economic Theory, 53(1), 146172

[11] Leininger, Wolfgang, 1993, More efficient rent-seeking - a Münchhausen solution, Public Choice, 75(1), 43-62.

[12] Maskin, Eric, and Jean Tirole, 2001, Markov perfect equilibrium I, Observable actions, Journal of Economic Theory, 100(2), 191-219.

[13] Müller, Holger M. and Karl Wärneryd, 2001, Inside versus outside ownership: a political theory of the firm, RAND Journal of Economics, $32(3), 527-541$.

[14] Wärneryd, Karl, 2000, In defense of lawyers: Moral hazard as an aid to cooperation, Games and Economic Behavior, 33(1), 145-158. 


\section{CESifo Working Paper Series}

(for full list see www.cesifo-group.de)

1549 Ruediger Pethig, Nonlinear Production, Abatement, Pollution and Materials Balance Reconsidered, September 2005

1550 Antonis Adam and Thomas Moutos, Turkish Delight for Some, Cold Turkey for Others?: The Effects of the EU-Turkey Customs Union, September 2005

1551 Peter Birch Sørensen, Dual Income Taxation: Why and how?, September 2005

1552 Kurt R. Brekke, Robert Nuscheler and Odd Rune Straume, Gatekeeping in Health Care, September 2005

1553 Maarten Bosker, Steven Brakman, Harry Garretsen and Marc Schramm, Looking for Multiple Equilibria when Geography Matters: German City Growth and the WWII Shock, September 2005

1554 Paul W. J. de Bijl, Structural Separation and Access in Telecommunications Markets, September 2005

1555 Ueli Grob and Stefan C. Wolter, Demographic Change and Public Education Spending: A Conflict between Young and Old?, October 2005

1556 Alberto Alesina and Guido Tabellini, Why is Fiscal Policy often Procyclical?, October 2005

1557 Piotr Wdowinski, Financial Markets and Economic Growth in Poland: Simulations with an Econometric Model, October 2005

1558 Peter Egger, Mario Larch, Michael Pfaffermayr and Janette Walde, Small Sample Properties of Maximum Likelihood Versus Generalized Method of Moments Based Tests for Spatially Autocorrelated Errors, October 2005

1559 Marie-Laure Breuillé and Robert J. Gary-Bobo, Sharing Budgetary Austerity under Free Mobility and Asymmetric Information: An Optimal Regulation Approach to Fiscal Federalism, October 2005

1560 Robert Dur and Amihai Glazer, Subsidizing Enjoyable Education, October 2005

1561 Carlo Altavilla and Paul De Grauwe, Non-Linearities in the Relation between the Exchange Rate and its Fundamentals, October 2005

1562 Josef Falkinger and Volker Grossmann, Distribution of Natural Resources, Entrepreneurship, and Economic Development: Growth Dynamics with Two Elites, October 2005 
$1563 \mathrm{Yu}-\mathrm{Fu}$ Chen and Michael Funke, Product Market Competition, Investment and Employment-Abundant versus Job-Poor Growth: A Real Options Perspective, October 2005

1564 Kai A. Konrad and Dan Kovenock, Equilibrium and Efficiency in the Tug-of-War, October 2005

1565 Joerg Breitung and M. Hashem Pesaran, Unit Roots and Cointegration in Panels, October 2005

1566 Steven Brakman, Harry Garretsen and Marc Schramm, Putting New Economic Geography to the Test: Free-ness of Trade and Agglomeration in the EU Regions, October 2005

1567 Robert Haveman, Karen Holden, Barbara Wolfe and Andrei Romanov, Assessing the Maintenance of Savings Sufficiency Over the First Decade of Retirement, October 2005

1568 Hans Fehr and Christian Habermann, Risk Sharing and Efficiency Implications of Progressive Pension Arrangements, October 2005

1569 Jovan Žamac, Pension Design when Fertility Fluctuates: The Role of Capital Mobility and Education Financing, October 2005

1570 Piotr Wdowinski and Aneta Zglinska-Pietrzak, The Warsaw Stock Exchange Index WIG: Modelling and Forecasting, October 2005

1571 J. Ignacio Conde-Ruiz, Vincenzo Galasso and Paola Profeta, Early Retirement and Social Security: A Long Term Perspective, October 2005

1572 Johannes Binswanger, Risk Management of Pension Systems from the Perspective of Loss Aversion, October 2005

1573 Geir B. Asheim, Wolfgang Buchholz, John M. Hartwick, Tapan Mitra and Cees Withagen, Constant Savings Rates and Quasi-Arithmetic Population Growth under Exhaustible Resource Constraints, October 2005

1574 Christian Hagist, Norbert Klusen, Andreas Plate and Bernd Raffelhueschen, Social Health Insurance - the Major Driver of Unsustainable Fiscal Policy?, October 2005

1575 Roland Hodler and Kurt Schmidheiny, How Fiscal Decentralization Flattens Progressive Taxes, October 2005

1576 George W. Evans, Seppo Honkapohja and Noah Williams, Generalized Stochastic Gradient Learning, October 2005

1577 Torben M. Andersen, Social Security and Longevity, October 2005

1578 Kai A. Konrad and Stergios Skaperdas, The Market for Protection and the Origin of the State, October 2005 
1579 Jan K. Brueckner and Stuart S. Rosenthal, Gentrification and Neighborhood Housing Cycles: Will America's Future Downtowns be Rich?, October 2005

1580 Elke J. Jahn and Wolfgang Ochel, Contracting Out Temporary Help Services in Germany, November 2005

1581 Astri Muren and Sten Nyberg, Young Liberals and Old Conservatives - Inequality, Mobility and Redistribution, November 2005

1582 Volker Nitsch, State Visits and International Trade, November 2005

1583 Alessandra Casella, Thomas Palfrey and Raymond Riezman, Minorities and Storable Votes, November 2005

1584 Sascha O. Becker, Introducing Time-to-Educate in a Job Search Model, November 2005

1585 Christos Kotsogiannis and Robert Schwager, On the Incentives to Experiment in Federations, November 2005

1586 Søren Bo Nielsen, Pascalis Raimondos-Møller and Guttorm Schjelderup, Centralized vs. De-centralized Multinationals and Taxes, November 2005

1587 Jan-Egbert Sturm and Barry Williams, What Determines Differences in Foreign Bank Efficiency? Australian Evidence, November 2005

1588 Steven Brakman and Charles van Marrewijk, Transfers, Non-Traded Goods, and Unemployment: An Analysis of the Keynes - Ohlin Debate, November 2005

1589 Kazuo Ogawa, Elmer Sterken and Ichiro Tokutsu, Bank Control and the Number of Bank Relations of Japanese Firms, November 2005

1590 Bruno Parigi and Loriana Pelizzon, Diversification and Ownership Concentration, November 2005

1591 Claude Crampes, Carole Haritchabalet and Bruno Jullien, Advertising, Competition and Entry in Media Industries, November 2005

1592 Johannes Becker and Clemens Fuest, Optimal Tax Policy when Firms are Internationally Mobile, November 2005

1593 Jim Malley, Apostolis Philippopoulos and Ulrich Woitek, Electoral Uncertainty, Fiscal Policy and Macroeconomic Fluctuations, November 2005

1594 Assar Lindbeck, Sustainable Social Spending, November 2005

1595 Hartmut Egger and Udo Kreickemeier, International Fragmentation: Boon or Bane for Domestic Employment?, November 2005

1596 Martin Werding, Survivor Benefits and the Gender Tax Gap in Public Pension Schemes: Observations from Germany, November 2005 
1597 Petra Geraats, Transparency of Monetary Policy: Theory and Practice, November 2005

1598 Christian Dustman and Francesca Fabbri, Gender and Ethnicity - Married Immigrants in Britain, November 2005

1599 M. Hashem Pesaran and Martin Weale, Survey Expectations, November 2005

1600 Ansgar Belke, Frank Baumgaertner, Friedrich Schneider and Ralph Setzer, The Different Extent of Privatisation Proceeds in EU Countries: A Preliminary Explanation Using a Public Choice Approach, November 2005

1601 Jan K. Brueckner, Fiscal Federalism and Economic Growth, November 2005

1602 Steven Brakman, Harry Garretsen and Charles van Marrewijk, Cross-Border Mergers and Acquisitions: On Revealed Comparative Advantage and Merger Waves, November 2005

1603 Erkki Koskela and Rune Stenbacka, Product Market Competition, Profit Sharing and Equilibrium Unemployment, November 2005

1604 Lutz Hendricks, How Important is Discount Rate Heterogeneity for Wealth Inequality?, November 2005

1605 Kathleen M. Day and Stanley L. Winer, Policy-induced Internal Migration: An Empirical Investigation of the Canadian Case, November 2005

1606 Paul De Grauwe and Cláudia Costa Storti, Is Monetary Policy in the Eurozone less Effective than in the US?, November 2005

1607 Per Engström and Bertil Holmlund, Worker Absenteeism in Search Equilibrium, November 2005

1608 Daniele Checchi and Cecilia García-Peñalosa, Labour Market Institutions and the Personal Distribution of Income in the OECD, November 2005

1609 Kai A. Konrad and Wolfgang Leininger, The Generalized Stackelberg Equilibrium of the All-Pay Auction with Complete Information, November 2005 